\section{GREEN AND PURPLE COPPER (II)- CHLORAMPHENICOL COMPLEXES IN METHANOL: EVIDENCE FOR THE COORDINATION OF DEPROTONATED AMIDE NITROGEN}

Sir :

Chloramphenicol having the possible three metal-binding sites, an amide and two hydroxy groups, is a well known antibiotic, but its reaction schemes with metal ions were not fully established, although the importance of metal interactions with antibiotics in relation to their subsequent actions has been discussed ${ }^{11}$. MEDVEDOVSKII et al proposed the structure $\mathbf{I}$ in Fig. 1 to the purple complex in reaction of $\mathrm{Cu}$ (II) with chloramphenicol in alkaline aqueous solution $^{2)}$. On the other hand, a green $\mathrm{Cu}$ (II)-chloramphenicol complex was isolated from methanol by FAZAKERLEY et $\mathrm{al}^{3)}$, who were unable to characterize the coordination mode in this complex. In a recent communication, JEREMIC et al concluded that the amide group was not involved in coordination in the purple complex suggesting the structure II in Fig. 1 ${ }^{4)}$.

In this paper we propose structures for the two kinds of complexes colored green and purple, which were formed in the reaction of $\mathrm{Cu}$ (II) and chloramphenicol under different $\mathrm{pH}$ conditions. A characterization of these complexes in metha-

Fig. 1. Proposed structures for Cu(II)-chloramphenicol complexes ${ }^{2,4)}$.

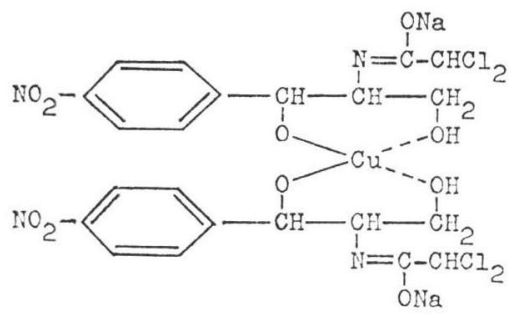

(I)
Fig. 2. ESR spectra of green (A) and purple (B) $\mathrm{Cu}$ (II)-chloramphenicol complexes in methanol at room temperature.

chloramphenicol - $\mathrm{KOH}-\mathrm{Cu}(\mathrm{II})=2: 4: 1$ (A), $2: 6: 1(\mathrm{~B})$

[chloramphenicol] $=2 \times 10^{-2} \mathrm{M}$

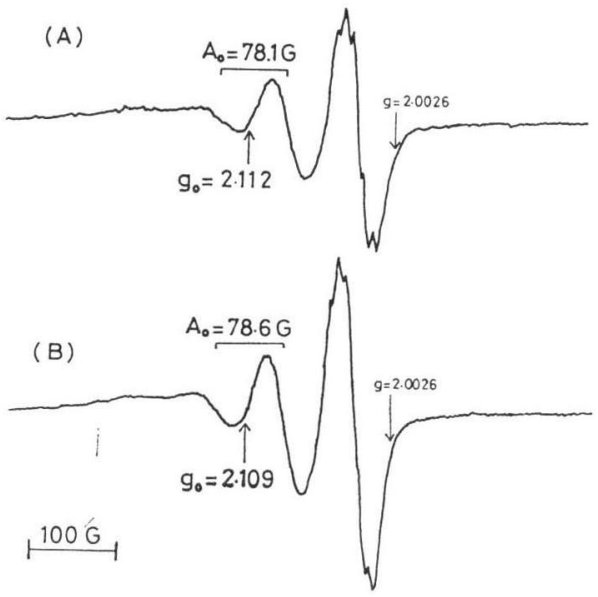

nol demonstrates that $\mathrm{Cu}$ (II) is bound to the nitrogen atom of deprotonated amide groups.

Chloramphenicol, $\mathrm{D}(-)$-threo-2-dichloroacetamido-1- $p$ - nitrophenyl - 1, 3 - propenediol, was obtained from Sigma Chemical Company. The methanol solution which contained 2:1 chloramphenicol and $\mathrm{Cu}$ (II) was titrated with methanolic $\mathrm{KOH}$ solution. As moles of $\mathrm{KOH}$ added per mole of chloramphenicol were two and three, the very stable green and purple colors were developed exhibiting the absorption maxima at $600 \mathrm{~nm}(\varepsilon=59)$ and $545 \mathrm{~nm}(\varepsilon=58)$, respectively. This shows clearly the presence of three coordination sites in chloramphenicol and also that in the green and purple complexes the metalbinding sites are two and three, respectively. Further, these titration and optical data suggested the presence of the coordination to $\mathrm{Cu}$ (II) from the deprotonated amide nitrogen in chloramphenicol ${ }^{5)}$. The compositions of the two complexes were found to be $2: 1$ in the ratio of ligand<smiles>[R]C1OC2(OCC1[N+](=O)OCC)OCC([N+](=O)OCC)C([R])O2</smiles> 
Fig. 3. Infrared spectra of purple (a), green (b) $\mathrm{Cu}$ (II)chloramphenicol complexes and chloramphenicol (c) in methanol.

Chloramphenicol - $\mathrm{KOH}$ $\mathrm{Cu}(\mathrm{II})=$ (a) $2: 6: 1$, [chlorampnenicol] $=6 \times 10^{-2} \mathrm{M}$; (b) $2: 4: 1$, [chloramphenicol] $=$ $6.7 \times 10^{-2} \mathrm{M}$; (c) [chloramphenicol $]=10^{-1} \mathrm{M}$

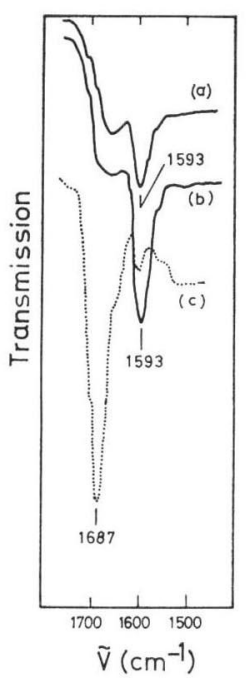

to $\mathrm{Cu}$ (II) by the molar ratio method, corresponding well with the result of JeREMIC et $a l^{4)}$. The two complexes showed unique and almost the same $C D$ spectra with each other with the sign $(-+-)$ above $400 \mathrm{~nm}$ and the purple complex gave a larger magnitude than the green one.

Involvement of the two nitrogen atoms as the metal-binding sites in the green and purple 1:2 $\mathrm{Cu}$ (II)-chloramphenicol was unequivocally demonstrated by ESR detection of the ligand hyperfine splittings (5 lines) due to the equivalent nitrogen atoms $\left({ }^{14} \mathrm{~N}, \mathrm{I}=1\right)$ (Fig. 2 ). The presence of the deprotonated amide nitrogen bound to $\mathrm{Cu}$ (II) in both complexes was further corroborated by monitoring the frequencies of carbonyl groups with the IR spectra measured in methanol (Fig. 3). The band at $1593 \mathrm{~cm}^{-1}$ in both complexes is assigned to the carbonyl group of the amides which involve deprotonated amide nitrogens bound to $\mathrm{Cu}(\mathrm{II})^{5,6)}$.

From these data, we propose that $\mathrm{Cu}$ (II)chloramphenicol green complex has two coordination sites with $\mathrm{Cu}$ (II), the deprotonated amide nitrogen and oxygen attached to $\mathrm{Cl}$ or $\mathrm{C} 3$ forming a tetracoordinated square planar configuration. The purple one has three sites, the deprotonated amide nitrogen and two oxygen attached to $\mathrm{C} 1$ and $\mathrm{C} 3$ forming a hexacoordinated octahedral configuration (Fig. 4). At present we can not answer which oxygen atom attached to $\mathrm{C} 1$ or $\mathrm{C} 3$ is used to form the chelation in the green complex.

Further investigations are under way to establish this point.
Fig. 4. Possible coordination modes of green (A) and purple (B) $\mathrm{Cu}$ (II)-chloramphenicol complexes in methanol.

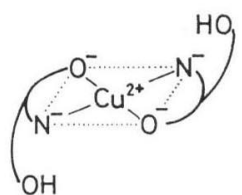

( A )

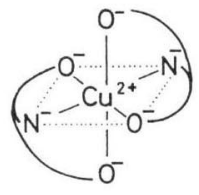

( B )

\section{Acknowledgment}

We are grateful to Prof. K. AKI, Faculty of Medicine, University of Tokushima, for measurements of CD spectra and Miss A. Nigi for skillful technical assistance. Gratitude is also due to Dr. M. SHibuYa, Faculty of Pharmaceutical Sciences, University of Tokushima, for his helpful advice and discussion.

\section{Hiromu Sakurai SHigeru SHIMOMURA \\ *KazuhiKo IshizU}

Faculty of Pharmaceutical Sciences, University of Tokushima, Scho-machi 1, Tokushima 770, Japan *Faculty of Sciences, Ehime University, Matsuyama, Ehime 790, Japan

(Received November 12, 1979)

\section{References}

1) Weinberg, E. D.: Known and suspected role of metal coordination in actions of antimicrobial drugs. Fed. Proc. 20: 132 136, 1961

2) MedvedovskiI, A. A. \& Y. Y. Fialkov: Structure of a copper-levomycetin complex. Farm. Zh. (Kiev) 28: 47 52, 1973

3) Farakerley, G. V.; P. W. Linder \& L. R. NASSIMBEN: Complexation of copper (II) by chloramphenicol. Inorg. Nucl. Chem. Lett. 9: 1069 1072, 1973

4) Jeremic, M.; A. A. Javanovic \& V. Bojovic: Copper (II)-chloramphenicol complex formation in methanol and aqueous solution. Inorg. Nucl. Chem. Lett. 14: 473 477, 1978

5) Kim, M. K. \& A. E. Martell: Copper (II) complexes by glycylglycine. Biochemistry 3 : $1170 \sim 1175,1964$

6) Kim, M. K. \& A. E. Martell: Copper (II) complexes of triglycine and tetraglycine. J. Am. Chem. Soc. 88: 914 918, 1966 